The updated plan will focus on 5 key strategic priorities, including professional and leadership development, scholarship, workforce recruitment and retention, policy advocacy, and professional relationships. The SPC is taking into account current and future issues faced by family medicine educators as it reviews 71 areas of importance and hones in on a prioritized list of strategies.

The committee will also examine the plan's alignment with Family Medicine for America's Health, including meeting faculty development needs, aligning family medicine entrustable professional activities into training, and improving clerkship sites.

SPC members include: Sam Cullison, MDi Mary Hall, $\mathrm{MD}_{i}$ John Saultz, MDi Beat Steiner, MD, $\mathrm{MPH}_{i}$ Larry Mauksch, MEd; Sarina Schrager, MDi Gretchen Dickson, MDi Steven Zweig, MD; and Stacy Brungardt, CAE.

The SPC will be working on the update through fall 2014 with plans to have a preliminary draft of the 2015-2018 Strategic Plan for review by the STFM Board of Directors in February 2015. STFM uses its strategic plan to guide the organization and its activities. The original plan was developed in 2011 for 2012-2014

Traci Nolte

STFM Director of Publications and Community

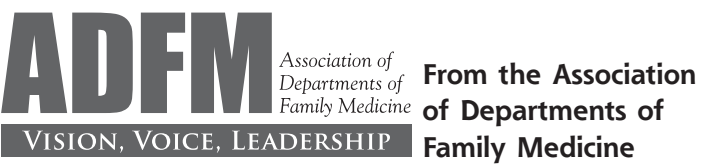

Ann Fam Med 2014;12:481-482. doi: 10.1370/afm.1702.

\section{EVOLVING PERSPECTIVES ON POPULATION HEALTH MANAGEMENT}

Health care costs are unevenly distributed, with a small percent of patients accounting for most health care costs in this country. ${ }^{1,2} \mathrm{~A}$ population health perspective is necessary to understand and address the complex needs of patients in the high risk, high cost segment.

In the late 1980s and 1990s, managed care, characterized by "gatekeeping" and heavy-handed utilization authorization, was a version of population cost management. ${ }^{3}$ Contemporary population health approaches, exemplified by highly integrated delivery systems such as Kaiser Permanente and Geisinger are achieving demonstrable success in the Triple Aims of better care, healthy people/healthy communities, and affordable care. ${ }^{4}$ Current approaches to managing the most complex chronically ill patients range from turning over their care to highly specialized academic medical centers to building a longitudinal relationship with a primary care medical home employing highly functional interprofessional teams. In contrast to the managed care of the 1990s, the current medical home models are without strict gatekeeping and promote a cooperative relationship between primary care and specialists to create a highly coordinated medical neighborhood.

Academic health centers will always deliver quaternary services that few community providers can provide and will maintain a unique patient mix. They cannot succeed, however, in the new health care paradigm of population health without a strong primary care base. Primary care physicians provide the majority of care to patients with chronic illness in the United States. ${ }^{5}$ Nearly one-half (42\%) of patients with chronic illness have more than a single condition ${ }^{6}$ and are, therefore, ill-suited for disease-specific, specialty-based medical homes. Primary care physicians comprehensively attend to the multiple medical needs and social needs of these patients, while collaborating with specialists as appropriate. These patients with multimorbidity are not a static group rather, they frequently move from health to serious medical exacerbation and back to better health. These transitions in health status accompany changes in their life situations, which is why having primary care-based population management and continuity of relationships is critical. Mounting evidence indicates that advanced models of primary care are increasing value, especially for this subgroup of patients in the highest tier of medical costs. ${ }^{7}$

We, in the Association of Departments of Family Medicine (ADFM), recognize that academic health centers are not Kaiser Permanente and Geisinger. Many departments of family medicine around the country are vigorously engaged in the movement to transform care and to create high-performing medical homes and medical neighborhoods at academic health centers. A major pressure most academic health centers are currently facing is a need to enhance primary care capabilities to provide even the institution's own employees with highly accessible, well-coordinated, affordable care. We have devoted considerable effort in ADFM to understand how we can help move our academic health centers from volume-based to valuebased care delivery ${ }^{8}$ with the ultimate goal of delivering the Triple Aim to all populations served by these large institutions.

As we look to the future, we need to partner with others to proactively facilitate work of many individuals and organizations to address delivery of health care to populations within our communities. We applaud 
the innovative work by individual family physicians such as Jeff Brenner from Camden, New Jersey, who has demonstrated how health care costs can be cut by finding community "hot spots" where emergency departments are over-utilized. ${ }^{9}$ We commend the Association of American Medical Colleges (AAMC) for publishing their report on how academic medical centers of the future must be system-based to survive. ${ }^{9}$ In a recently published report, the AAMC describes 4 options for academic medical centers to move toward a system identity, from forming a new system, to partnering, to merging, or to facing the reality of shrinking in isolation. ${ }^{10}$ Within ADFM, we are tracking how departments of family medicine (DFMs) are leading health care transformation within their academic health centers. Many of our DFMs are actively engaged in moving to team-based care, improving delivery of preventive services, and promoting more appropriate use of consultations and referrals. ${ }^{11}$ We will continue to collaborate with others who share the goal of using population health management approaches to improve affordable health care for the nation.

ADFM Executive Committee: Paul James, $M D_{\text {; }}$

Anton Kuzel, MDi Barbara Thompson, $M D_{\text {i }}$

Ardis Davis, MSW; and Kevin Grumbach, MD

\section{References}

1. Berk M, Monheit A, Hagan M. How the US spent its health care dollar: 1929-1980. Health Aff (Millwood); 1988;7(4):46.60.

2. Berk ML, Monheit AC. The concentration of health expenditures: an update. Health Aff (Millwood). 1992;11(4):145-149.

3. Blendon RJ, Brodie M, Benson JM, et al. Understanding the managed care backlash. Health Aff (Millwood). 1998;17(4):80-94.

4. US Department of Health and Human Services. 2011 Report to Congress: National Strategy for Quality Improvement in Health Care. March 2011. http://www.ahrq.gov/workingforquality/nqs/ nqs2011annlrpt.htm.

5. Sharma MA, Cheng N, Moore M, Coffman M, Bazemore AW. Patients with high-cost chronic conditions rely heavily on primary care physicians. J Am Board Fam Med. 2014;27(1):11-12.

6. Barnett K, Mercer SW, Norbury M, Watt G, Wyke S, Guthrie B. Epidemiology of multimorbidity and implications for health care, research, and medical education: a cross-sectional study. Lancet. 2012;380(9836):37-43.

7. Patient-Centered Primary Care Collaborative. The Medical Home's Impact on Cost, Quality. An Annual Update of the Evidence, 2012-2013. http://www.pcpcc.org/resource/ medical-homes-impact-cost-quality.

8. Perkins A, Miller H, Davis A, et al. ADFM's 2013 winter meeting focus: moving to value-based health care. Ann Fam Med. 2013;11(4): 383-384.

9. Camden Coalition of Healthcare Providers. [Blog post]. http://www. camdenhealth.org/finding-medical-hotspots-helps-cut-cost/.

10. Association of American Medical Colleges (AAMC). Advisory Panel on Health Care. Advancing the Academic Health System for the Future. Washington, DC: AAMC; 2014.

11. Harris A, Tallia A, et al. Health system change and academic departments. Ann Fam Med. 2014;12(2):180-181.

\section{A END Drom the Association \\ of Family Medicine \\ Residency Directors}

Ann Fam Med 2014;12:482-483. doi: 10.1370/afm.1703.

\section{PROGRAM DIRECTOR TURNOVER}

One of the most widely used Association of Family Medicine Residency Directors (AFMRD) member benefits is the e-mail discussion list, commonly referred to as the Listserv. Here is where more than 600 program directors and associate program directors have the opportunity to share information and support. It's also where announcements that a program director is leaving are commonly posted, usually accompanied by the introduction of a new program director. Less frequent but no less important are announcements about family medicine residency programs closing.

The announcements of program director changes may create the perception that program director turnover is increasing, yet recent data shows otherwise. The program director turnover rate has been stable for the past 12 years, with 8 of the past 12 years in the $12 \%$ to $14 \%$ range. The lowest turnover was just below $12 \%$ in 2008-2009; the highest percentage was $17.09 \%$ in 2004 2005. The percentages are reported by the Accreditation Council for Graduate Medical Education based upon the number of new program directors, including interim program directors. Thus, some programs have 2 program director changes even though only 1 program changed. The percentage turnover would be even smaller if it were counted by program changes, not program director changes.

Even the absolute number of program director changes has been remarkably stable. The number of new program directors in the past 12 years has ranged from 84 in 2002-2003 to a low of 54 in 2008-2009, while the total number of family medicine programs has ranged from a high of 497 in 2001-2002 to a low of 450 in 2009-2010.

The number of new and withdrawn programs affects the number of program directors. The largest number of withdrawn programs since 2002 occurred that year, with no new programs added in 2002. Since then, the number of new programs has been generally growing while the number of withdrawn programs has been generally decreasing. Since 2009, the number of new programs has outweighed the number of withdrawn programs. In 2012-2013 and 2013-2014, the rate of increase of new programs nearly doubled, to 13 and 14 new programs respectively, above the previous highest rate of 7 new 